\title{
EDITORIAL
}

\section{WHAT INDUSTRY CAN DO FOR PARAPLEGIA}

EVERYONE pays lip service to the idea of paraplegics becoming completely integrated into the community by providing them with reasonably paid work. So often both sides begin to weary of the effort, the project tends to languish and finally is relinquished. The challenge has been taken up in Japan, with the declared intention of making paraplegics and tetraplegics financially independent and integrating them permanently into the industrial scene. The aim includes equality with other 'normal' workers.

The project was commenced by Japan Sun Industries in 1965 with seven wheelchair bound workers and at first was only a tiny sheltered workshop.

In the course of 16 years this has become a large factory for the severely disabled. Employed are I 69 able bodied workers and 473 disabled, the latter including 60 individuals with spinal injury and seven tetraplegics. Others have muscular dystrophy, are totally blind, thalidomide victims, etc. All these workers are remunerated on a commercial basis and are also stock holders in the company. Among the businesses concerned is the

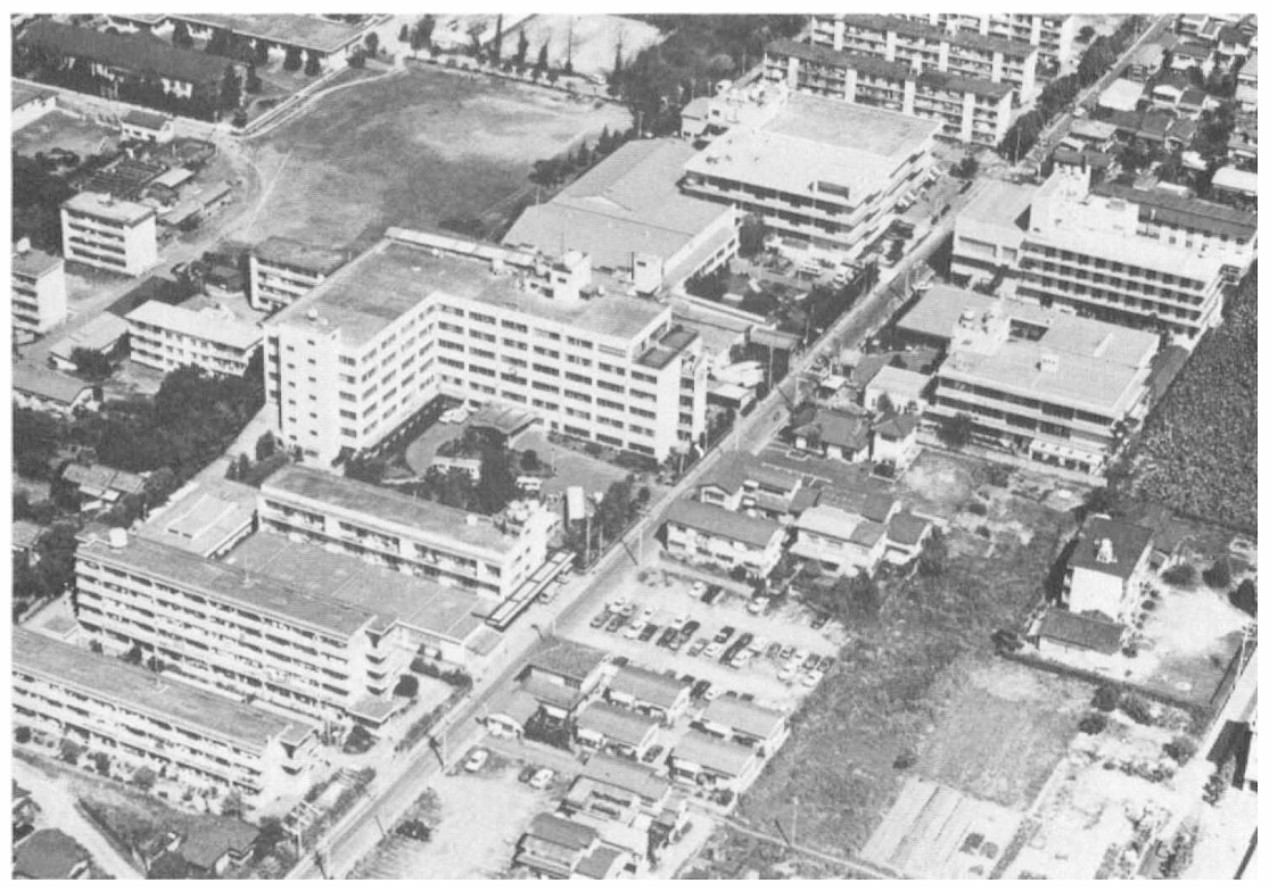

FIG. I

Whole view of the Japan Sun Industries. 


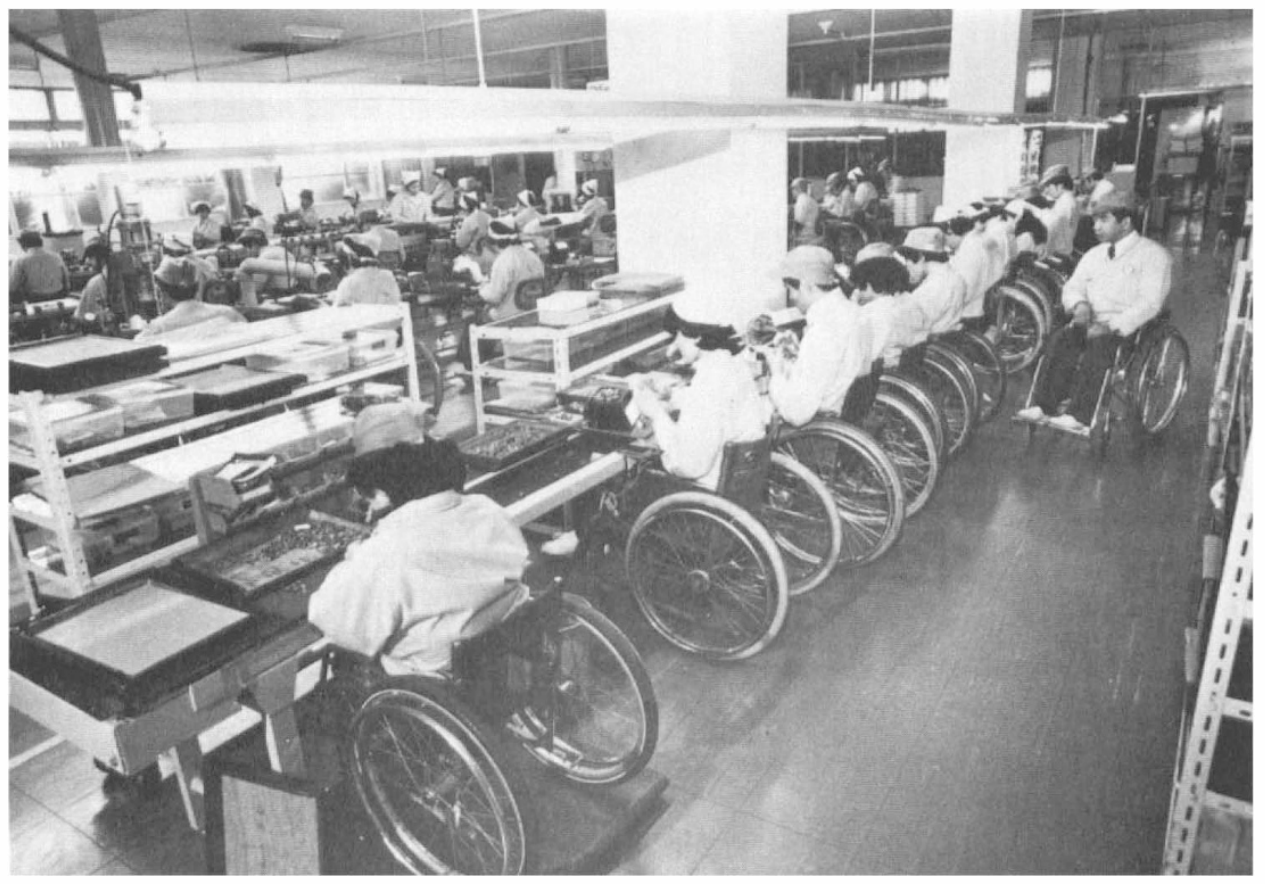

FIG. 2

Omron-Sun electric company in Japan Sun Industries.

Sony-Sun Corporation, the Honda Sun Industry and the Omron Sun Electronics.

The Human Resources Institute was established by Japan Industries sometime ago with a view to establishing the type of work most suitable for the disabled. The Institute came down firmly on the conveyor belt system which allows the paraplegic to be as efficient as the able-bodied worker.

In the factory it was found that the wheelchair was much speedier and more practical than using crutches even if the worker can use these. At first some trouble was experienced with pressure sores but this was resolved by pushing up the buttocks every two hours during work. The rate of non-attendance of the paraplegics is 2.6 per cent. For the tetraplegics work had been provided by remodelling of machine tools using a mouth switch, light touch switch and new boring machines.

New developments include a supermarket 'Sun Store', which was opened in 1977 using six disabled workers as the main workforce. Automatic price indicators are equipped so that the customers have minimal delay. Also there is now a branch of the bank present on the premises and this employs three disabled clerks among its staff.

One interesting development of this project is that the number of marriages has increased with 102 couples married with I 7 children, necessitating a nursery and baby sitter service.

The motto of this splendid project is 'No charity, give a chance', and indeed this is similar to something that Ludwig Guttmann said many years ago-'From a cripple to a taxpayer', but he did add the warning 


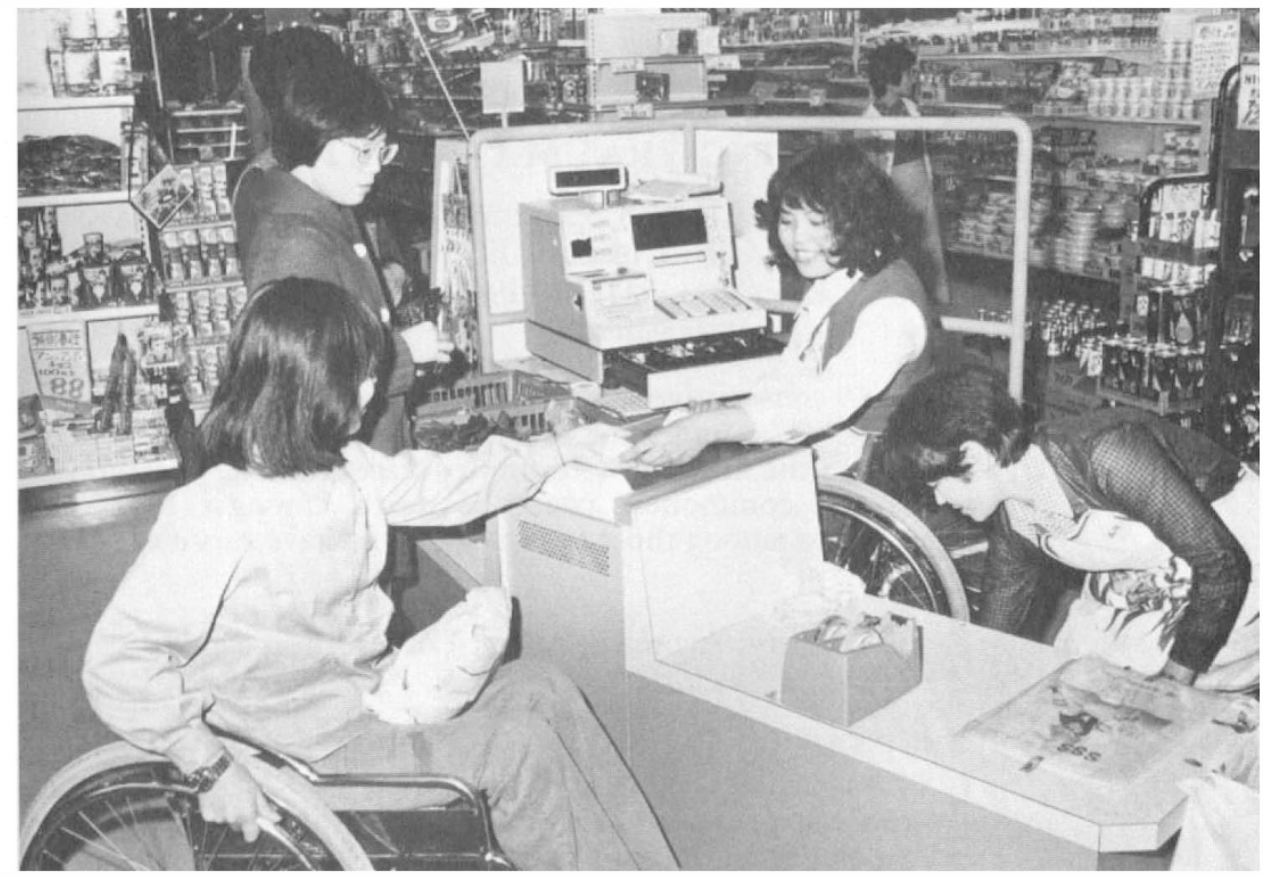

FIG. 3

Supermarket 'Sun Store' operated by seven wheelchair-bound.

that 'It cannot be supposed that a man who is unwilling to work will be motivated to work by the fact that he has a spinal injury'. All of those involved with this project deserve the greatest possible praise for this magnificent achievement.

Yutaka Nakamura,

Fapan. 